TITLE:

\title{
Photographic study of hydrodynamics of drops of aqueous polymer solution impinging on hot solid
}

\section{AUTHOR(S):}

Fujimoto, Hitoshi; Watanabe, Shohei; Okamoto, Takahiko; Hama, Takayuki; Takuda, Hirohiko

\section{CITATION:}

Fujimoto, Hitoshi ...[et al]. Photographic study of hydrodynamics of drops of aqueous polymer solution impinging on hot solid. Experimental Thermal and Fluid Science 2015, 60: 66-74

\section{ISSUE DATE:}

2015-01

URL:

http://hdl.handle.net/2433/191116

\section{RIGHT:}

@ 2014 Elsevier Inc.; この論文は出版社版でありません。引用の際には 出版社版をご確認ご利用ください。; This is not the published version. Please cite only the published version. 


\title{
Photographic Study of Hydrodynamics of Drops of Aqueous Polymer Solution Impinging on Hot Solid
}

\author{
Hitoshi Fujimoto ${ }^{1}$, Shohei Watanabe ${ }^{1}$, Takahiko Okamoto², \\ Takayuki Hama ${ }^{1}$ and Hirohiko Takuda ${ }^{1}$
}

1. Graduate School of Energy Science, Kyoto University, Sakyo-ku, Kyoto 606-8501, Japan

2. Senior Technical Engineer, Daido Chemical Industry Company Limited, Technology Research Laboratory, Nara, 639-1037, Japan

\begin{abstract}
Spray-cooling methods are utilized in quench hardening and throughout the metal-forming industry. Aqueous solutions of water-soluble polymers are the typical quenchant. Although the impact behavior of the droplets has a great influence on the heat transfer between the hot metal surface and quenchant, the hydrodynamics of drops of aqueous polymer solutions are rarely studied. In this study, the collision of drops of an aqueous solution of polymer with a hot sapphire solid surface was investigated using strobe photography. A solution of $10 \mathrm{wt} \%$ polyoxyethylene polyoxypropylene glycol, with an average molecular weight of approximately 20,000, was used as the test polymer quenchant. Experiments were conducted with drop diameters in the range 2.09-2.42 mm, impact velocities from 0.83 to $1.25 \mathrm{~m} / \mathrm{s}$, and surface temperatures of 200, 350 , and $500{ }^{\circ} \mathrm{C}$. The effect of varying the temperature and the dimensionless Weber number on the collision behavior and drop evolution was investigated. Microscopic observations revealed that polymer residue remained on the surface when the temperature of the solid was equal to or less than $350{ }^{\circ} \mathrm{C}$. At $500{ }^{\circ} \mathrm{C}$, drops impacting on the surface at low Weber numbers deformed into a thin disc, recoiled, and finally rebounded off the solid in a spray of mist. No polymer residue remained. The residence times of the rebounding drops after impact increased with the Weber number. In
\end{abstract}


addition, the measured residence times were slightly longer than some experimentally determined formulae for simple compound liquid drops predict.

Keywords: Weber number, strobe photography, polymer quenchant, droplet dynamics, quenching 


\section{Introduction}

In the steel-making and metal-forming industries, quench hardening is widely utilized to strengthen carbon steels. In quench hardening, hot carbon steels are rapidly cooled by the application of the quenching medium [1]. During the cooling process, the microstructure of the steel is typically transformed from austenite to pearlite, ferrite, cementite, bainite, or martensite. The transformation of austenite to martensite occurs in the temperature range between the martensite start temperature and the martensite finish temperature. Because martensite has a slightly larger specific volume (or smaller density) than austenite, volume expansion occurs during martensitic transformations. When large, local temperature variations arise during quenching, the resultant thermal stresses and transformation stresses occasionally cause unwanted changes in the products, such as distortions in shape and crack initiation/development.

In quench hardening, submergence methods are widely used (see Fig. 1(a)). The hot materials are immersed in a quenchant (cooling fluid) bath to obtain rapid cooling rates [1]. Spray-cooling methods are also utilized, as illustrated in Fig. 1(b). Here, hot materials are cooled by the impingement of fluid directed from a spray jet. In both cooling methods, water is commonly employed as the quenchant, because it can achieve large heat removal rates. However, large cooling rates are associated with large temperature variations in hot materials and can lead to the aforementioned side effects. To prevent this, quenchants that provide heat removal rates smaller than water, such as aqueous solutions of water soluble polymers, are used [1].

The heat transfer from the hot materials to the polymer solution can be controlled by the chemical composition of the polymer and/or the concentration of the polymer in the aqueous solution. In quench hardening using the submergence method, the temperature of the quenchant is high in the vicinity of the hot material surfaces. When the polymer solution is heated above a specific point, called the "cloud point," the solubility of the polymer drastically decreases, and the separation of the polymer from the water occurs 
[2]. The separated polymer forms a film on the material surface, and this film reduces the local distortion or cracking because the temperature variations are reduced $[3,4]$.

The behavior of polymer solutions during immersion cooling is well-studied, but fundamental studies concerning aqueous polymer solutions during spray cooling are rare. In spray cooling, hot materials are cooled through the impingement of numerous liquid droplets. The impact behavior of the droplets has a great influence on the heat transfer between the hot metal surface and quenchant. There have been numerous studies on the collision dynamics of droplets with solids [5-7]. Most of studies were conducted using a single-component fluid or a simple compound fluid like water, ethanol, and fuel droplets. Some studies concerning the impact of polymer solution droplets have been conducted for inkjet printing [8]. Additionally, the effect of polymer additives on the collision behavior of water drops has been investigated at low polymer concentrations [9-11]. However, the hydrodynamics of drops of aqueous polymer solutions with the relatively high concentrations required for quench hardening have been studied only rarely, and fundamental knowledge of these issues is lacking.

The objective of this study was to experimentally analyze the collision behavior of drops of aqueous solutions of water-soluble polymer on a hot solid. This investigation was carried out using a two-dimensional strobe photography technique developed previously by the authors $[12,13]$. The effect of different solid temperatures and the impact inertia, as reflected in the Weber number, was studied. Also, the deformation behavior of drops on a solid at $500{ }^{\circ} \mathrm{C}$ were interpreted in terms of the Weber number and previously reported formulae obtained from experiments on simple component liquids with a low molecular weight.

\section{Experiments}

\subsection{Setup}


Figure 2 shows a schematic diagram of the experimental apparatus used to observe the collision of the drops with the hot solid. The setup included a syringe unit to generate isolated drops, a dispenser to feed air into the syringe unit, a gas-tight tank to pressurize the syringe, a heated test surface on which the drops impinged, and the observation equipment for strobe photography.

The aqueous polymer solution was loaded in the syringe unit. During each drop impact test, a small amount of air was supplied to the syringe unit from the dispenser. The polymer solution was transported to the nozzle attached below the syringe, then a drop formed at the nozzle exit, increased in size, and eventually detached under the influence of gravity. The nozzle unit was maintained at a preset temperature by an isothermal unit. The falling drops were detected by the optical sensor used to generate the strobe-light trigger signal, and then the drops impacted on the horizontal test surface. The impact velocity of the drops was adjusted by varying the nozzle-to-substrate distance.

The test surface was firmly mounted on a copper base with an embedded cartridge electric heater. The copper base was attached to a multi-axis transverse and tilt stage. The test surface was a transparent sapphire disk $2 \mathrm{~mm}$ thick and $30 \mathrm{~mm}$ in diameter with very smooth surface. The temperature of the surface was maintained at a preset value by a temperature controller. The temperature was monitored using a K-type thermocouple and infrared thermography. The thermocouple attached to the solid surface was used to control the electric power supplied to the heater unit. Also, a thin coat of blackbody paint with an emissivity of 0.94 was applied to a region of the sapphire surface in order to perform temperature measurements using an infrared camera. The drops impinged not on the blackbody paint but on the uncoated sapphire. The temperature of the solid surface, $T_{w}$, was set to a value in the range $200-500{ }^{\circ} \mathrm{C}$. The maximum temperature of the solid was determined by the limitations of the electronic heater. The measurement accuracy of the temperature was within $\pm 20{ }^{\circ} \mathrm{C}$, including the deviation of the temperature during the experiments with $T_{w}=500^{\circ} \mathrm{C}$. 
The collision behaviors of the drops with the solid surface were studied using a two-directional flash photography method developed by the present authors [12, 13]. The photography setup included two digital still cameras with an effective spatial resolution of $5184 \times 3456$ pixels and three strobe lights, as shown in Figure 2. One digital camera ("Camera A" in the figure) and a pair of strobe light units ("Strobe lights A, B”) were aligned and timed to obtain side-view, double-exposed, and backlit images of the droplets. Camera A was used to measure the impact conditions, including the pre-impact diameters of drops, the impact velocity, and/or drop shapes during the collisions. Another camera (“Camera B”) and flash unit ("Strobe light C”) were arranged to provide top-view images of the drops. When the trigger signals occurred, a flash controller activated the three flash units independently at different preset delay times with a resolution of $1 \mu \mathrm{s}$.

The droplet images were collected only when the flash units were triggered. This photography system could take one pair of images from Cameras A and B per impact test. The time evolution of the droplet shape for a given set of impact conditions was reconstructed by taking many images of different drops with different flash timings. The details of this measurement method were presented in our previous studies [12, 13].

The pre-impact diameter of the droplets, $d_{p}$, was controlled the range 2.09 to $2.42 \mathrm{~mm}$, and the impact velocity, $v$, varied from 0.83 to $1.25 \mathrm{~m} / \mathrm{s}$. The experimental uncertainties were mainly derived from the scatter of drop size at the nozzle exit. The scatters of the pre-impact diameter and the impact velocity were within $\pm 0.08 \mathrm{~mm}$ and $\pm 0.02 \mathrm{~m} / \mathrm{s}$, respectively.

\subsection{Dimensionless parameters}

The dimensionless time, $\tau$, based on the impact inertia is defined as

$$
\tau=\frac{t_{e} v}{d_{p}}
$$


where $t_{e}$ represents the elapsed time after the drop touches the solid. The Weber number We is defined as

$$
W e=\frac{\rho v^{2} d_{p}}{\sigma}
$$

where $\rho$ and $\sigma$ are the density and surface tension coefficient, respectively, of the pre-impact drops. The range of Weber numbers tested in the present study was 27-67.

\subsection{Test solution}

Polyoxyethylene-polyoxypropylene glycol, with chemical formula $\mathrm{HO}-\left(\mathrm{C}_{2} \mathrm{H}_{4} \mathrm{O}\right)_{a}-\left(\mathrm{C}_{3} \mathrm{H}_{6} \mathrm{O}\right)_{b}-\left(\mathrm{C}_{2} \mathrm{H}_{4} \mathrm{O}\right)_{c}-\mathrm{H}$, was adopted as the test polymer. The exact composition was determined by the ratio of $a+c$ to $b$, which was 75 to 25 . The measured molecular weight of the test polymer was approximately 20,000. The test solution/quenchant was made by diluting the polymer with distilled water to $10 \mathrm{wt} \%$. Note that this test polymer and the concentrations employed in this study are those used in actual quench hardening.

The measured physical properties of the test solution are listed in Table 1. (The properties of water are also tabulated for reference.) The densities and specific heats of the test solution were similar to water, while the kinetic viscosity of the test solution was approximately 8 times greater than the kinetic viscosity of water at $40{ }^{\circ} \mathrm{C}$. Also, the kinetic viscosity of the test solution decreases steeply with increases in the temperature. The test solution was colorless and transparent at room temperature. At the cloud point, the liquid becomes clouded due to the difference in the refractive indices of each liquid [2]. The measured cloud point of the test solution was approximately $75^{\circ} \mathrm{C}$.

\subsection{Preliminary experiments}


When droplets of the test solution impinged on a hot solid surface above the boiling temperature of water but below a certain temperature, only the water/solvent evaporated, and the gelled polymer remained on the solid. At higher temperatures, no polymer residue remained. The former case is inconvenient for the present experiments, because numerous images of different drops were taken under the same experimental conditions. If any polymer residue remained on the solid surface after an impact, the surface would have to be wiped very carefully with clean wet tissue to maintain uniformity. Otherwise, a polymer layer would build up with accumulated runs, and the surface condition would change.

In order to investigate the temperature range over which the polymer residue remained, simple preliminary experiments were conducted as follows: A single drop of test solution was applied to the clean, hot surface, and the impact was observed by conventional video-recording at 60 frames per second. Then, the electric power supply to the heater unit was cut and the test surface was cooled by natural convection to the atmosphere. After cooling, the sapphire disk was removed from the heater unit and its surface was observed with an optical microscope.

Figure 3 shows the evaporation behavior of a quenchant drop on the hot solid for $T_{w}$ $=$ (a) $200{ }^{\circ} \mathrm{C}$, (b) $300{ }^{\circ} \mathrm{C}$ and (c) $350{ }^{\circ} \mathrm{C}$. The pre-impact drop diameter was approximately $2.3 \mathrm{~mm}$ and the impact velocity was $1.12 \mathrm{~m} / \mathrm{s}$. The exposure time of each frame is $1 / 125$ s. In Figure 3(a), the drop became clouded and strong nucleate boiling was observed $0.03 \mathrm{~s}$ after the drop impact. Thereafter, the volume of the drop decreased with time due to evaporation of water. The drop was partially transparent during the interval 0.5-3.0 s, indicating that gelled polymer was present. Finally, some gelled-polymer residue remained near the impact point at $4.0 \mathrm{~s}$. In Figure 3(b), the water evaporated over a shorter time period than that in Figure 3(a) because of greater heat transfer from the solid to liquid. In the interval $0.15-1.5 \mathrm{~s}$, some gelled residue remained, though this decreases gradually over time (1.5-9.0 s). In Figure 3(c), the drop floated off of the surface at $0.03 \mathrm{~s}$. Unlike in the previous two cases, there was no 
complete liquid/solid contact. At $0.7 \mathrm{~s}$, only a small amount of residue was observed. This decreased with time (0.7-2.0 s) and eventually disappeared (2.0 s). Similar experiments were conducted with $T_{w}=400{ }^{\circ} \mathrm{C}$ and $500{ }^{\circ} \mathrm{C}$ (not shown), and no residue was observed in the video images.

Figure 4 shows photomicrographs of the residual polymer on clean sapphire surfaces after a single droplet impact at various surface temperatures. The other impact conditions were the same as those for the results in Figure 3. In Figure 4(a), $T_{w}=300{ }^{\circ} \mathrm{C}$, and in Figure 4(b) $T_{w}=350{ }^{\circ} \mathrm{C}$. Some residue can be observed near the drop impact point in these images, although the polymer apparently disappeared in the video-recorded observations in Figures 3(b) and 3(c). At $400{ }^{\circ} \mathrm{C}$ (Figure 4(c)) and $500{ }^{\circ} \mathrm{C}$ (Figure 4(d)), no polymer residue remained on the solid surface. In all figures, there were numerous "fuzzy" spots in the background; these are not polymer residue. In this study, a reflected-light microscope was used. Light for observation impinged on the sapphire plate from above, was reflected off of the surface, and entered the lens system. Since the sapphire is transparent, some incident light passed through the sapphire surface and was reflected at the rear surface. These rear-surface reflections are present in the figure images (though they are slightly out of focus). At the rear surface, a light-blocking coating was applied to facilitate the capture of clear overhead images of the drops. The fuzzy spots are patterns in the out-of-focus, light-blocking coating.

An additional experiment was conducted at $T_{w}=500{ }^{\circ} \mathrm{C}$. A few hundred isolated drops impacted on the solid without any intermediate wiping, and afterwards the test surface was observed using an optical microscope near the drop impact point. Little residue was observed on the surface. These results indicate that, at $T_{w}=500{ }^{\circ} \mathrm{C}$, the test polymer was thermally decomposed into low-molecular-weight compounds, which then evaporated. Thus, in the experiments described below, the solid surface was cleaned after each impact test when the temperature of solid was equal to or less than $350{ }^{\circ} \mathrm{C}$. At $500{ }^{\circ} \mathrm{C}$, the experiments were conducted without any surface cleaning. 


\section{Results and discussion}

\subsection{Effect of varying the solid surface temperature}

The effects of varying the temperature of the solid surface on the impact behavior of the drops were studied under conditions where the Weber number was approximately 40 . The detailed experimental conditions are tabulated in Table 2. The images in Figure 5 show the deformation behavior of a drop on the surface at $T_{w}=200{ }^{\circ} \mathrm{C}$ and were taken by Camera B. The elapsed time,- $t_{e}$, is indicated in each panel, and the dimensionless elapsed time, $\tau$, defined in Equation (1), is indicated in parenthesis. At $t_{e}=0.54 \mathrm{~ms}$, the drop was transparent, and bubbles were observed at the liquid/solid interface. A relatively large bubble observed at the impact point is indicated by an arrow. The drop spread radially, deformed into a distorted thin circular disk, and then recoiled. The test liquid was in direct contact with the solid the entire time, and vapor bubbles are always present in the liquid. The drop appeared clouded at $118 \mathrm{~ms}$ because the local temperature of the quenchant exceeded the cloud point $\left(=75^{\circ} \mathrm{C}\right)$ due to heat transfer from the solid. Thereafter, the water evaporated slowly and only residual test polymer remained on the solid (not shown).

Figure 6 indicates the collision behavior of a drop impacting on the hot surface at $T_{w}$ $=350{ }^{\circ} \mathrm{C}$. At $t_{e}=0.86 \mathrm{~ms}$, a relatively large bubble, indicated by an arrow, appeared near the impact point. Also, many bubbles were observed on the periphery of the spreading liquid drop. At $t_{e}=1.81 \mathrm{~ms}$, numerous small droplets were propelled upward from the thin liquid film region indicated by a circle. These are formed by the "blowout" of boiling solvent at the liquid/air interface. A bulge of liquid developed at the center of the drop, indicated by an arrow, at $t_{e}=2.77 \mathrm{~ms}$. The periphery of liquid showed regularly spaced radial bulges. Thereafter, liquid split into several smaller droplets ( $t_{e}=5.48-13.2 \mathrm{~ms}$ ). At $T_{w}=350{ }^{\circ} \mathrm{C}$, the degree of direct liquid/solid contact at later times was reduced compared to the case of $T_{w}=200{ }^{\circ} \mathrm{C}$.

The formation of a liquid bulge near the impact point is one of characteristic features 
of the collision of a polymer solution drop with a hot solid. Since a relatively large bubble was always seen before the appearance of the liquid bulge, the bulge is probably formed due to the following mechanism: At the moment of droplet impact, some air was trapped between the solid and the liquid [14]. The trapped air bubble functioned as a nucleation site for the phase transformation. As the temperature of solid was much higher than the boiling temperature of water, evaporation of water occurred, and the bubble grew larger, as illustrated in Figure 7(a). On the other hand, the drop height decreased because of the inertia of impact. When the thickness of the liquid was equal to the size of growing bubble, a vacancy appeared (Figure 7(b)), and the liquid moved inward to fill the vacancy (Figure 7(c)), resulting in an upward flow at the center of the impact point (Figure 7(d)). This behavior was also present at higher temperatures, as shown in Figures 8, 9, and 10.

Figure 8 shows the results for $T_{w}=500{ }^{\circ} \mathrm{C}$. The drop deformed into a circular disk at $t_{e}=1.31 \mathrm{~ms}$. At $t_{e}=2.63 \mathrm{~ms}$, vapor/liquid interface is present across the entire drop, with the result that the drop looked hazy. A bulge of liquid was observed at $t_{e}=4.32 \mathrm{~ms}$. Thereafter, the liquid recoiled and was elongated upward in the shape of a bowling pin. Eventually, it rebounded off the heated surface. The rebounding drop looked lightly clouded. The shape of the drops in this case is roughly axisymmetric, unlike the previous results in Figures 5 and 6.

Figure 8(b) shows the double-exposure, backlit images of a drop at $t_{e}=14.2 \mathrm{~ms}$, taken by Camera A. Two different drop images are superimposed in the figure, although they are a same drop. One is a spherical drop; this image was exposed during the first flash before the impact, and was used to determine the impact conditions [12]. The other is the bowling-pin-shaped drop exposed during the second flash. In the region between the solid surface and the bottom of redounding drop, some mist was observed. The formation mechanism of the mist can be explained as follows: When the drop initially touched the hot solid surface, some water evaporated, and the polymer was thermally decomposed into low-molecular-weight compounds, some of which could be 
evaporated themselves. When the drop rebounded off the solid, it induced some upward air flow near the solid, and the decomposed products and/or evaporated water were transported upward, cooled, and condensed into mist.

\subsection{Effect of varying the Weber number}

In the cases of single-component liquids or simple compound liquids, including water, ethanol, or liquid fuel, the Weber number is a key parameter describing the collision of drops with a hot solid surface in the film boiling regime [15]. If the drop impacts the surface at small Weber numbers, it rebounds from the solid without any disintegration of the drop. At high Weber numbers, the drop splits into pieces during the collision. Since it was observed in the images in Figure 8 that the drop of polymer solution rebounded off the surface at $W e=40$, the experiment was conducted at a larger Weber numbers and under otherwise similar conditions. Figure 9 shows the results for $T_{w}=$ $500{ }^{\circ} \mathrm{C}$ and $W e=67$. The drop impacted, spread radially, and deformed into a disk. The formation of a liquid bulge was observed. At $t_{e}=3.70 \mathrm{~ms}$, the circular liquid film partially broke, and the drop split into pieces. The motion of liquid is apparently three-dimensional at later times. In addition, experiments carried out at various Weber numbers and $T_{w}=500{ }^{\circ} \mathrm{C}$ indicated that the critical boundary values at which the disintegration of drop occurred was approximately $W e=60$.

\subsection{Maximum spreading diameter and resident time of drops}

Here, the deformation behavior of drops at small Weber numbers is interpreted. Figure 10 shows the deformation behavior of the drops impinging on a hot sapphire surface for parameters $d_{p}=2.34 \mathrm{~mm}, v=0.98 \mathrm{~m} / \mathrm{s}$, and $T_{w}=500{ }^{\circ} \mathrm{C}$. Both the top-view images taken by Camera B and the side-view, double-exposure images of droplets taken by Camera A are shown. Since the Weber number in this case (We $=45$ ) was only 
slightly larger than that for the results shown in Figure 8, the deformation behavior of the drops was similar to that in Figure 8, such as the formation of a liquid bulge and the development of mist. Also, the drop finally rebounded away from the solid entirely.

It was observed that the drop shape was roughly axi-symmetric during the collision, so the drop motion could be investigated from a quantitative perspective. Figure 11 shows the time evolution of (a) the dimensionless diameter, $d / d_{p}$ of the drop and (b) the dimensionless spacing, $h / d_{p}$, between the bottom of rebounding drops and the solid. The definitions of these values are shown inset in Figure 11, and the data were directly measured from the side-view images taken by Camera A. The experimental conditions were the same as those for the experiment shown in Figure 10. The drop diameter increased with time, attained its maximum value at approximately $\tau=1.5$, then decreased. The scatter in the measured data was very small during the spreading process. At later times, the drop shape became three-dimensional, resulting in increased scatter. The drop rebounded off the surface at approximately $\tau=5.2$.

There are some experimentally derived formulae capable of predicting the maximum spreading diameters of drops, $d_{\max } / d_{p}$, and the dimensionless resident time of drops, $\tau_{r}$, on a hot surface (from the moment of impact to complete departure from the surface) as functions of the Weber number alone [16-18]. These include.

$$
\begin{aligned}
& d_{\max } / d_{p}=0.87 \sqrt{W e / 6}+2, \\
& d_{\max } / d_{p}=0.613 W e^{0.39}, \text { and } \\
& d_{\max } / d_{p}=0.093 W e^{0.074}+1 .
\end{aligned}
$$

Eqs. (3)-(5) were reported by Ueda et al. [16], Akao et al. [17], and Hatta et al. [18], respectively. Figure 12 shows the comparison of the empirical maximum spreading diameters of the drops of polymer solution and the predictions of the three formulae. The maximum spreading diameter increased with increases in We, and the empirical data are slightly smaller than the formulae predict at large Weber numbers.

Figure 13 depicts the relation between the dimensionless resident time of the drops and the Weber number. The measured resident time increased with increases in the 
Weber number. The measured values were in fair agreement with the formulae of Ueda et al. [16]

$$
\tau_{r}=0.25 \pi \sqrt{W e}
$$

and Hatta et al. [18]

$$
\tau_{r}=1.25 W e^{0.37} .
$$

The measured residence time was slightly larger than the formulae predict.

As previously mentioned, the test liquid is much more viscous than water. The separation of polymer and water occurs when the liquid is heated above the cloud point, and the separated polymer is a gel/non-Newtonian fluid with very high viscosity. Thus, large internal shear stresses are present in the liquid near the solid surface. Also, the polymer is probably in direct contact with the solid locally as well as temporally, resulting in large wall friction. As a consequence, the liquid inertia was reduced. This is the reason why the spreading diameter of the drop was smaller, and the resident time was larger, than the formulae for single-component or simple compound drops indicate.

\section{Conclusions}

The collisions of drops of an aqueous polymer solution with a hot surface were studied experimentally using strobe photography. The results obtained are summarized as follows:

(1) The evaporation behavior of the solution drops depends sensitively on the temperature, $T_{w}$, of the solid impact surface. When the temperature of the solid surface is less than $\approx 350{ }^{\circ} \mathrm{C}$, some polymer residue remained. At temperatures of $400{ }^{\circ} \mathrm{C}$ and $500{ }^{\circ} \mathrm{C}$, little polymer residue was found.

(2) The solid surface temperature strongly influenced the drop collision behavior at fixed Weber number, We. At $T_{w}=200{ }^{\circ} \mathrm{C}$ and $W e=40$, the droplet was in direct contact with the solid, and the water evaporated slowly. At $T_{w}=350{ }^{\circ} \mathrm{C}$ and $W e=40$, 
evaporation of water became active, and the drop split into several small droplets. Additionally, a bulge of liquid was observed at the center of the drop. At $T_{w}=$ $500{ }^{\circ} \mathrm{C}$ and $\mathrm{We}=40$, the drop was roughly axisymmetric. In the gap between the bottom of the rebounding drop and the solid surface, mist was observed.

(3) The deformation behaviors of drops on the solid at fixed temperature $\left(500^{\circ} \mathrm{C}\right)$ vary with the Weber number, and the results can be compared with formulae derived for single-component liquids. These formulae were roughly applicable for predicting the time-dependent droplet deformation. However, some discrepancies between the measured data and the formulae predictions existed; these are to the result of the high viscosity of the polymer and the separation of polymer and water. 


\section{References}

[1] G. E. Totten, C. E. Bates, and N. A. Clinton: Handbook of Quenchants and Quenching Technology, ASM International, 1993, ISBN 0-87170-448-X.

[2] P.I. Freeman and J.S. Rowlinson: Lower Critical Points in Polymer Solutions, Polymer: 1960, 1: 20-26.

[3] A.K. Sinha and B.P. Division, ASM Handbook, Volume 4: Heat Treating, ASM International, 1991, p. 601-619, ISBN 0-87170-379-3.

[4] H.M. Tensi, A. Stich, and G.E. Totten: Fundamentals About Quenching by Submerging, Proceeding of International Heat Treating Conference: Equipment and Process, 18-20 April 1994, Schaumburg, Illinois.

[5] M. Rein: Phenomena of liquid drop impact on solid and liquid surfaces, Fluid Dynamics Research: 1993, 12: 61-93.

[6] M. Rein: Interactions between drops and hot surfaces, In Drop-Surface Interactions. CISM Courses and Lectures no. 456, 2002, Springer-Verlag Wien New York: 185-217.

[7] A.L. Yarin: Drop Impact Dynamics: Splashing, Spreading, Receding, Bouncing, Annual Review of Fluid Mechanics: 2006, 38: 159-192.

[8] B.-J. deGans, P.C. Duineveld and U.S. Schubert: Inkjet Printing of Polymers: State of the Art and Future Developments, Advanced Materials: 2004, 16(3): 203-213.

[9] V. Bertola: Drop impact on a hot surface: effect of a polymer additive, Experiments in Fluids: 2004, 37: 653-664.

[10] V. Bertola and K. Sefiane: Controlling secondary atomization during drop impact on hot surfaces by polymer additives, Physics of Fluids: 2005, 17, AIP108104. 
[11] V. Bertola: An experimental study of bouncing Leidenfrost drops: Comparison between Newtonian and viscoelastic liquids, International Journal of Heat and Mass Transfer: 2009, 52(7-8): 1786-1793.

[12] H. Fujimoto, Y. Oku, T. Ogihara, and H. Takuda: Hydrodynamics and Boiling Phenomena of Water Droplets Impinging on Hot Solid: International Journal of Multiphase Flow: 2010, 36: 620-642.

[13] H. Fujimoto, R. Doi and H. Takuda: An Experimental Study on the Oblique Collisions of Water Droplets With a Smooth Hot Solid, Transactions of ASME, Journal of Fluids Engineering: 2012, 134 (7): art. no. 71301.

[14] H. Fujimoto, H. Shiraishi and N. Hatta: Evolution of liquid/solid contact area of a drop impinging on a solid surface: International Journal of Heat Mass Transfer: 2000, 43, 1673-1677.

[15] L.H.J. Wachters and N.A.J. Westerling: The heat transfer from a hot wall to impinging water drops in the spheroidal state: Chemical Engineering Science: 1966. 21, 1047-1056.

[16] T. Ueda, T. Enomoto, and M. Kanetsuki: Heat Transfer Characteristics and Dynamic Behavior of Saturated Droplets Impinging on a Heated Vertical Surface, Bulletins of JSME Series M: 1979, 22: 724-732.

[17] F. Akao, K. Araki, S. Mori and A. Moriyama: Deformation Behaviors of a Liquid Droplet Impinging onto Hot Metal Surface: Transaction of Iron Steel Institute of Japan: 1980, 20: 737-743.

[18] N. Hatta, H. Fujimoto, K. Kinoshita and H. Takuda: Experimental Study of Deformation Mechanism of a Water Droplet Impinging on Hot Metallic Surfaces above the Leidenfrost Temperature: Transactions of the ASME, Journal of Fluids Engineering: 1997, 119: 692-699. 


\section{List of figure and table captions}

Figure 1: Schematics of cooling methods typically used in quench hardening. (a) Submergence cooling, and (b) spray cooling.

Figure 2: Schematic of the experimental apparatus used to generate the droplets, observe their impact, and heat the test surface.

Figure 3: Evaporation behavior of drops on a solid surface at (a) $T_{w}=200{ }^{\circ} \mathrm{C}$, (b) $T_{w}=$ $300{ }^{\circ} \mathrm{C}$, and (c) $T_{w}=350{ }^{\circ} \mathrm{C}$.

Figure 4: Photomicrographs showing the residual polymer deposited on the solid surface at (a) $T_{w}=300{ }^{\circ} \mathrm{C}$, (b) $T_{w}=350{ }^{\circ} \mathrm{C}$, (c) $T_{w}=400{ }^{\circ} \mathrm{C}$, and (d) $T_{w}=500{ }^{\circ} \mathrm{C}$. Figure 5: Deformation behavior of drops impacting on the solid sapphire surface at $T_{w}$ $=200{ }^{\circ} \mathrm{C}$ for $d_{p}=2.32 \mathrm{~mm}, v=0.89 \mathrm{~m} / \mathrm{s}$, and $W e=38$.

Figure 6: Deformation behavior of drops impacting on the solid sapphire surface at $T_{w}$ $=350{ }^{\circ} \mathrm{C}$ for $d_{p}=2.34 \mathrm{~mm}, v=0.92 \mathrm{~m} / \mathrm{s}$, and $W e=39$.

Figure 7: Possible evolution mechanism of the liquid bulges.

Figure 8: Deformation behavior of drops impacting the sapphire surface at $T_{w}=500{ }^{\circ} \mathrm{C}$ for $d_{p}=2.38 \mathrm{~mm}, v=0.91 \mathrm{~m} / \mathrm{s}$, and $W e=40$. (a) Top view and (b) double-exposure side view.

Figure 9: Deformation behavior of drops impacting the sapphire surface at $T_{w}=500{ }^{\circ} \mathrm{C}$ for $d_{p}=2.17 \mathrm{~mm}, v=1.25 \mathrm{~m} / \mathrm{s}$, and $W e=67$.

Figure 10: Results for drop impacts at $T_{w}=500{ }^{\circ} \mathrm{C}$ for $d_{p}=2.34 \mathrm{~mm}, v=0.98 \mathrm{~m} / \mathrm{s}$, and We $=45$. (a) top view, and (b) side view (including pre-impact double exposure).

Figure 11: Time evolution of the drop diameter and the spacing between the bottom of the rebounding drop and the solid surface.

Figure 12: Empirical and theoretical relationship between the dimensionless maximum spreading diameter and the Weber number.

Figure 13: Empirical and theoretical relationship between the dimensionless residence time of drops on a hot surface and the Weber number.

Table 1: Physical properties of the test solution.

Table 2: List of experimental conditions. 


\section{Nomenclature}

$d_{\max } \quad$ maximum spreading diameter of droplet, $\mathrm{m}$

$d_{p} \quad$ pre-impact diameter of droplet, $\mathrm{m}$

$h \quad$ spacing between the bottom of rebounding droplet and solid surface, $\mathrm{m}$

$t_{e} \quad$ elapsed time after a droplet touches the solid surface, $\mathrm{s}$

$T_{w} \quad$ temperature of the solid surface, ${ }^{\circ} \mathrm{C}$

$v \quad$ impact velocity of the droplet, $\mathrm{m} / \mathrm{s}$

We Weber number, -

$\rho \quad$ liquid density, $\mathrm{kg} / \mathrm{m}^{3}$

$\sigma \quad$ surface tension, $\mathrm{N} / \mathrm{m}$

$\tau \quad$ dimensionless elapsed time, -

$\tau_{r} \quad$ dimensionless resident time of drop, - 


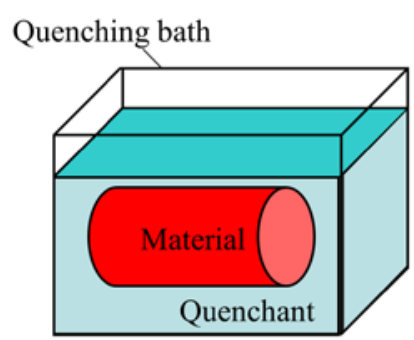

(a) Submergence cooling

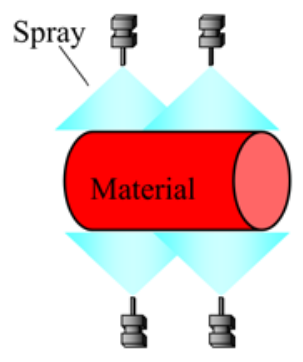

(b) Spray cooling

Figure 1: Schematics of cooling methods typically used in quench hardening. (a) Submergence cooling, and (b) spray cooling. 


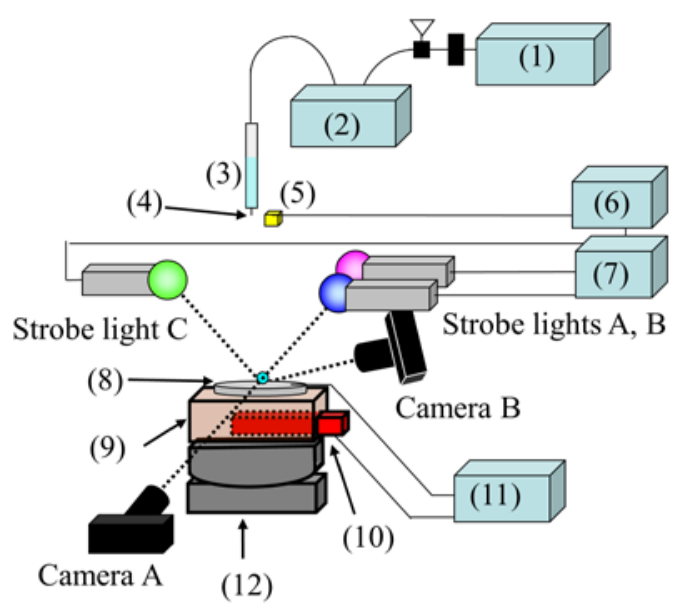

(1) air tank, (2) dispenser, (3) sylinge,

(4) nozzle equipped with isothermal unit,

(5) optical sensor, (6) delay timer,

(7) flash controller, (8) test surface,

(9) copper base, (10) electric heater,

(11) temperature controller,

(12) multi-axis transverse and tilt stage

Figure 2: Schematic of the experimental apparatus used to generate the droplets, observe their impact, and heat the test surface. 
(a) $T_{w}=200{ }^{\circ} \mathrm{C}$

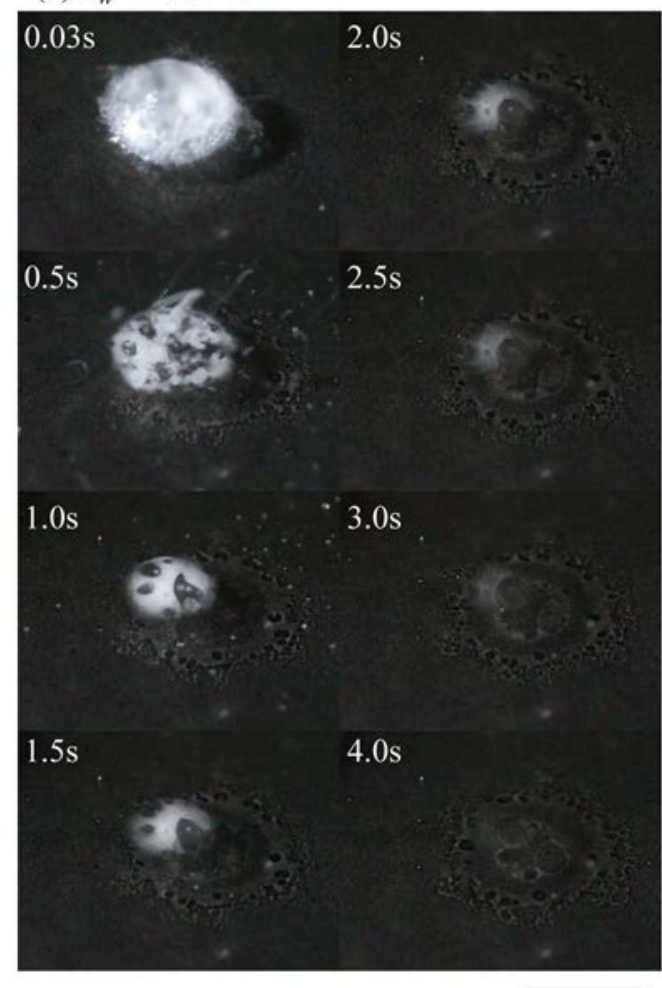

$3 \mathrm{~mm}$

(c) $T_{w}=350{ }^{\circ} \mathrm{C}$

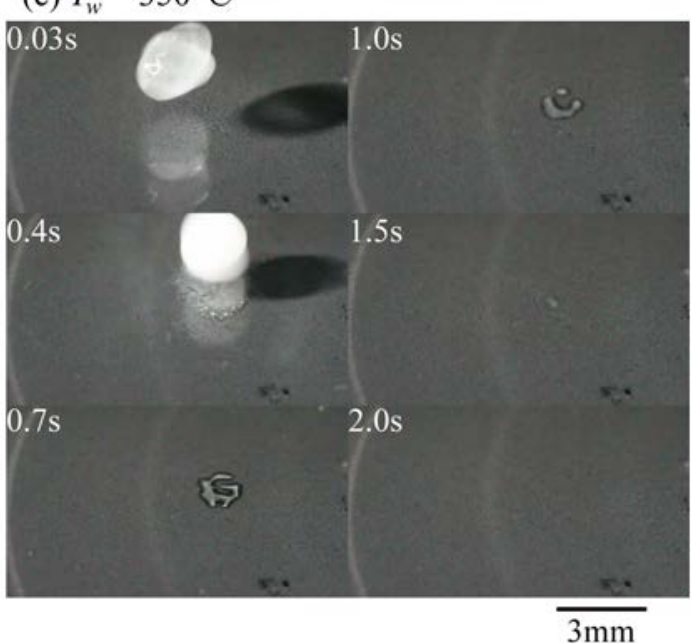

(b) $T_{w}=300{ }^{\circ} \mathrm{C}$

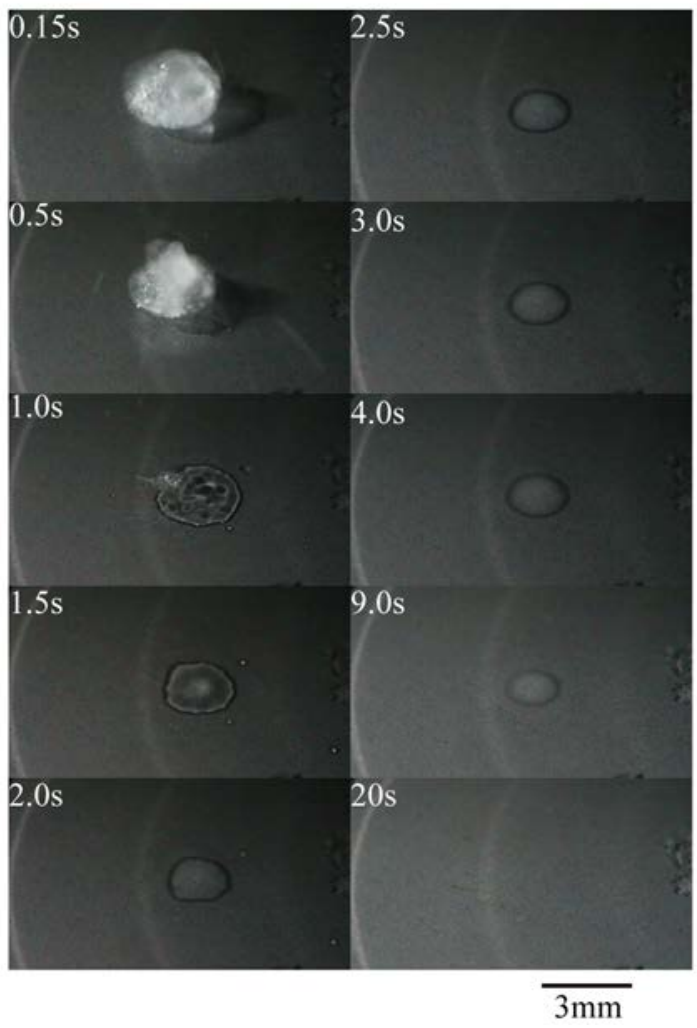

Figure 3: Evaporation behavior of drops on a solid surface at (a) $T_{w}=200{ }^{\circ} \mathrm{C}$, (b) $T_{w}=$ $300{ }^{\circ} \mathrm{C}$, and (c) $T_{w}=350{ }^{\circ} \mathrm{C}$. 

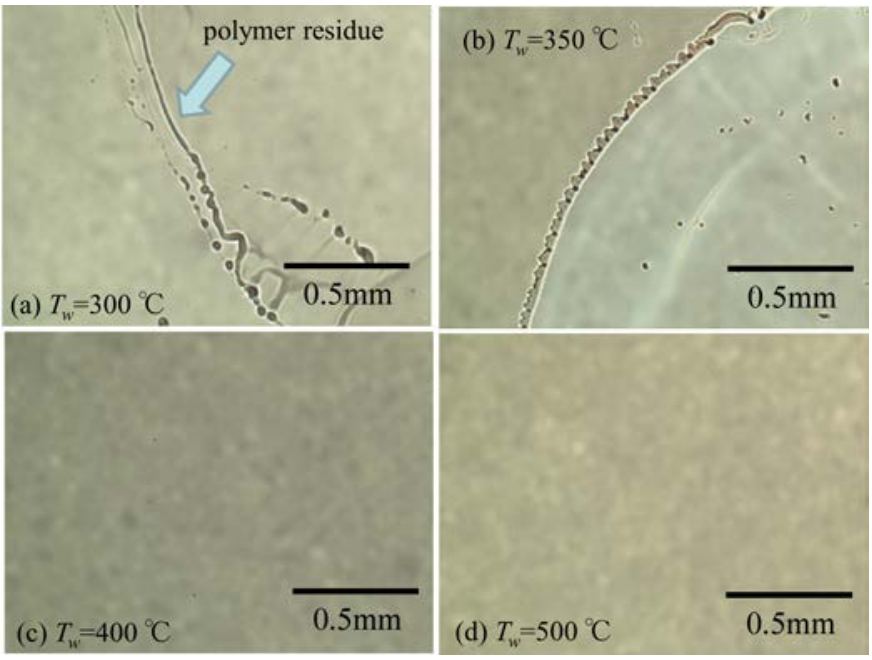

Figure 4: Photomicrographs showing the residual polymer deposited on the solid surface at (a) $T_{w}=300{ }^{\circ} \mathrm{C}$, (b) $T_{w}=350{ }^{\circ} \mathrm{C}$, (c) $T_{w}=400{ }^{\circ} \mathrm{C}$, and (d) $T_{w}=500{ }^{\circ} \mathrm{C}$. 


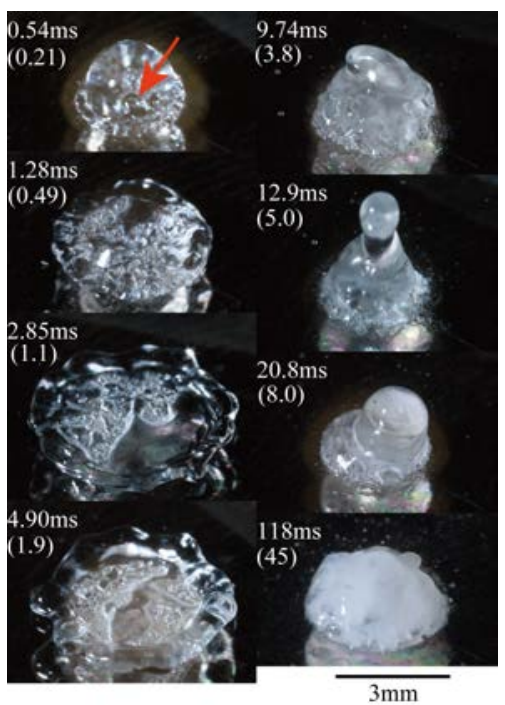

Figure 5: Deformation behavior of drops impacting on the solid sapphire surface at $T_{w}$ $=200{ }^{\circ} \mathrm{C}$ for $d_{p}=2.32 \mathrm{~mm}, v=0.89 \mathrm{~m} / \mathrm{s}$, and $W e=38$. 


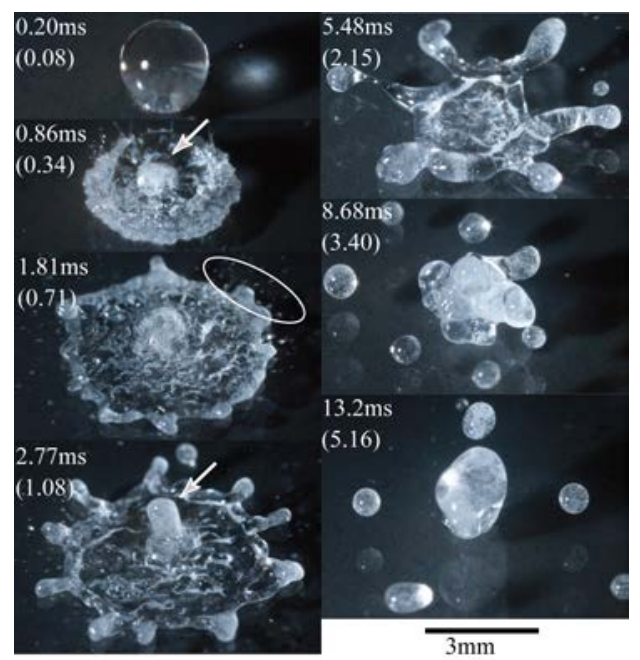

Figure 6: Deformation behavior of drops impacting on the solid sapphire surface at $T_{\mathrm{w}}$ $=350{ }^{\circ} \mathrm{C}$ for $d_{p}=2.34 \mathrm{~mm}, v=0.92 \mathrm{~m} / \mathrm{s}$, and $W e=39$. 
(a)

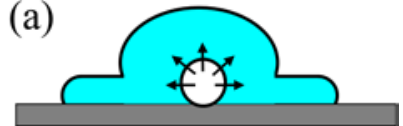

(b)

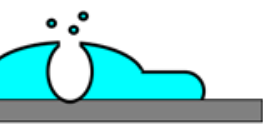

(c)

c) 戈

(d)

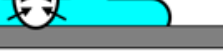

Figure 7: Possible evolution mechanism of the liquid bulges. 
(a)

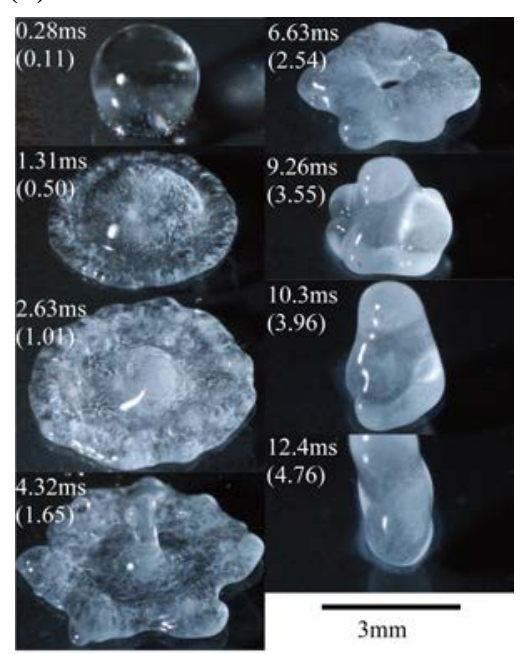

(b)

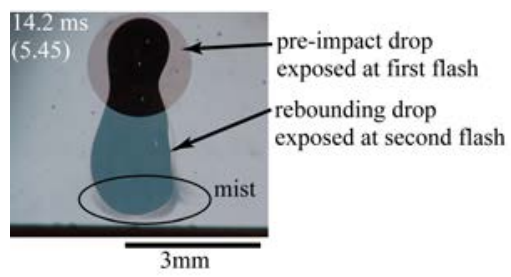

Figure 8: Deformation behavior of drops impacting the sapphire surface at $T_{w}=500{ }^{\circ} \mathrm{C}$ for $d_{p}=2.38 \mathrm{~mm}, v=0.91 \mathrm{~m} / \mathrm{s}$, and We $=40$. (a) Top view and (b) double-exposure side view. 


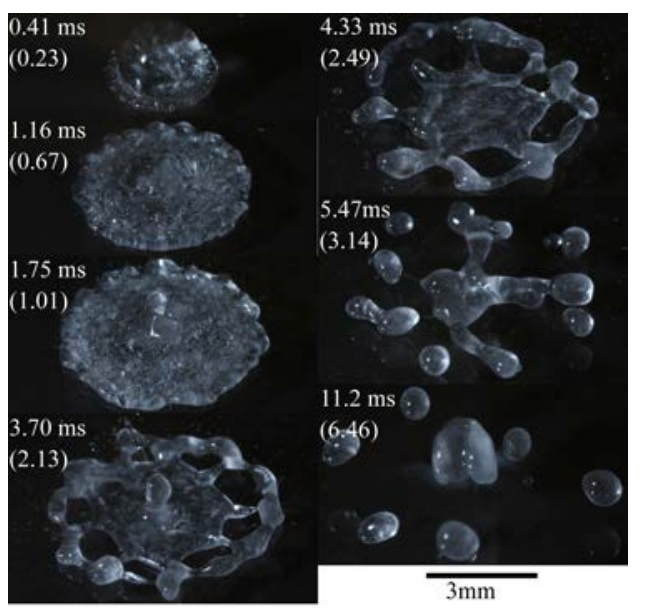

Figure 9: Deformation behavior of drops impacting the sapphire surface at $T_{w}=500{ }^{\circ} \mathrm{C}$ for $d_{p}=2.17 \mathrm{~mm}, v=1.25 \mathrm{~m} / \mathrm{s}$, and $W e=67$. 
(a)

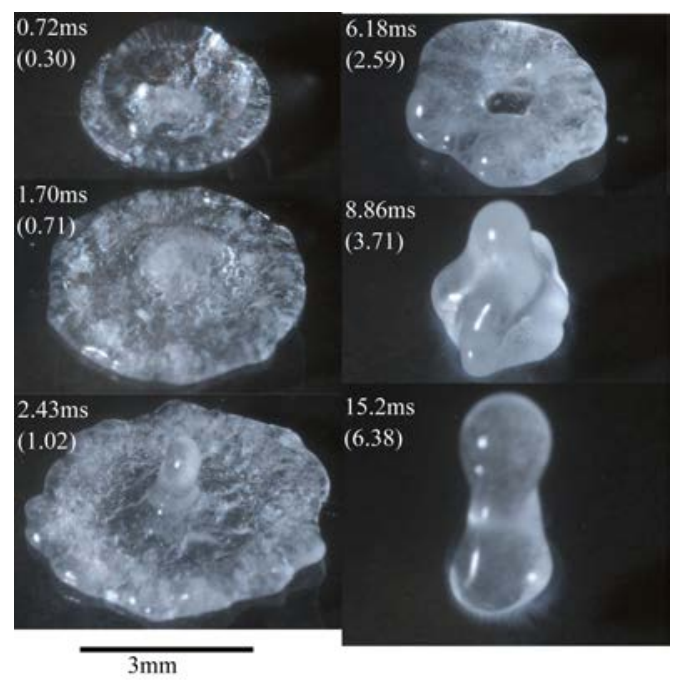

(b)

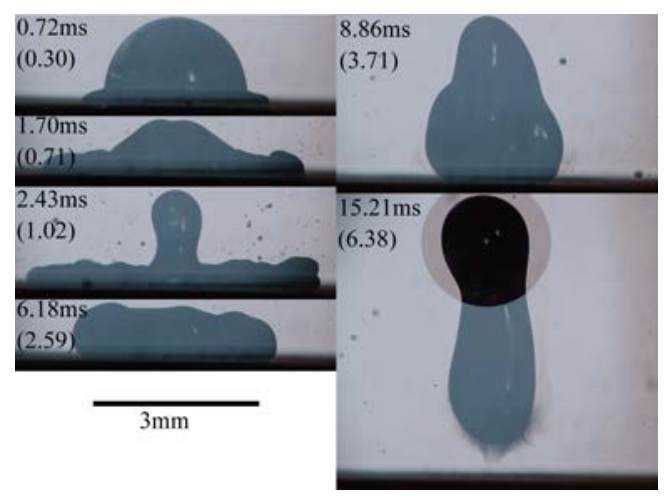

Figure 10: Results for drop impacts at $T_{w}=500{ }^{\circ} \mathrm{C}$ for $d_{p}=2.34 \mathrm{~mm}, v=0.98 \mathrm{~m} / \mathrm{s}$, and $W e=45$. (a) top view, and (b) side view (including pre-impact double exposure). 


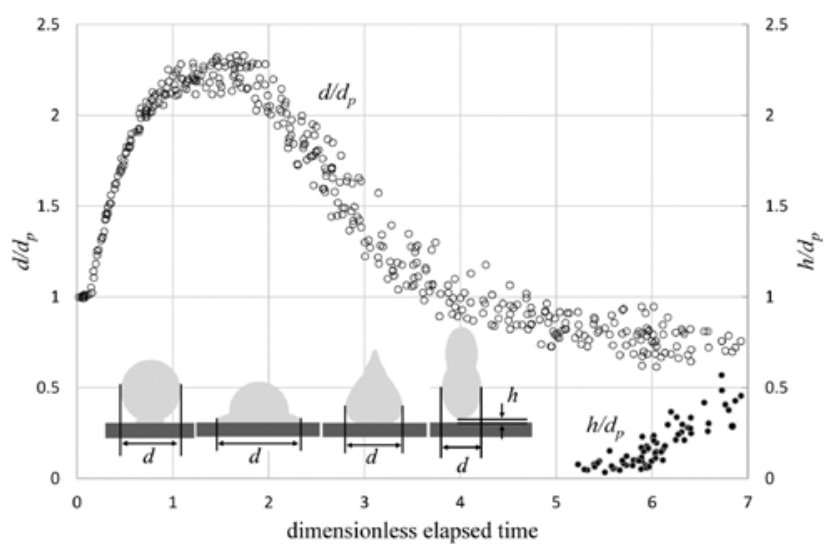

Figure 11: Time evolution of the drop diameter and the spacing between the bottom of the rebounding drop and the solid surface. 


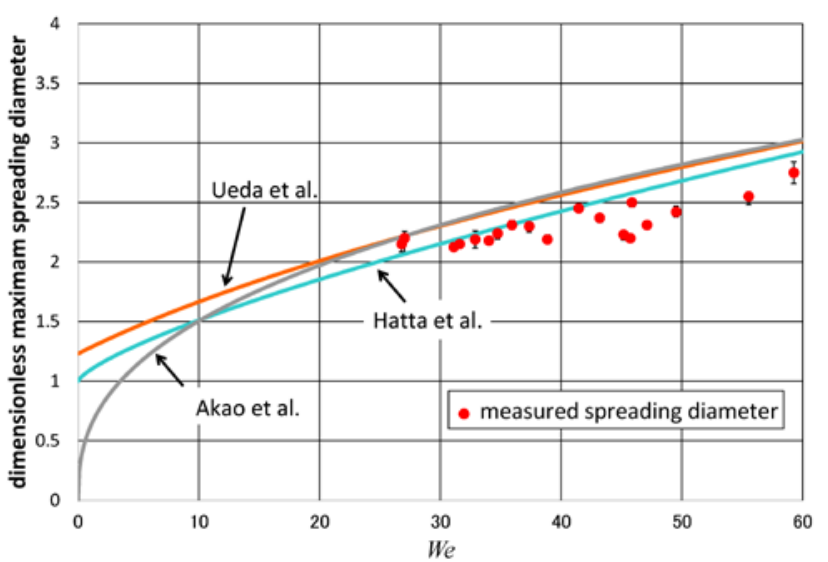

Figure 12: Empirical and theoretical relationship between the dimensionless maximum spreading diameter and the Weber number. 


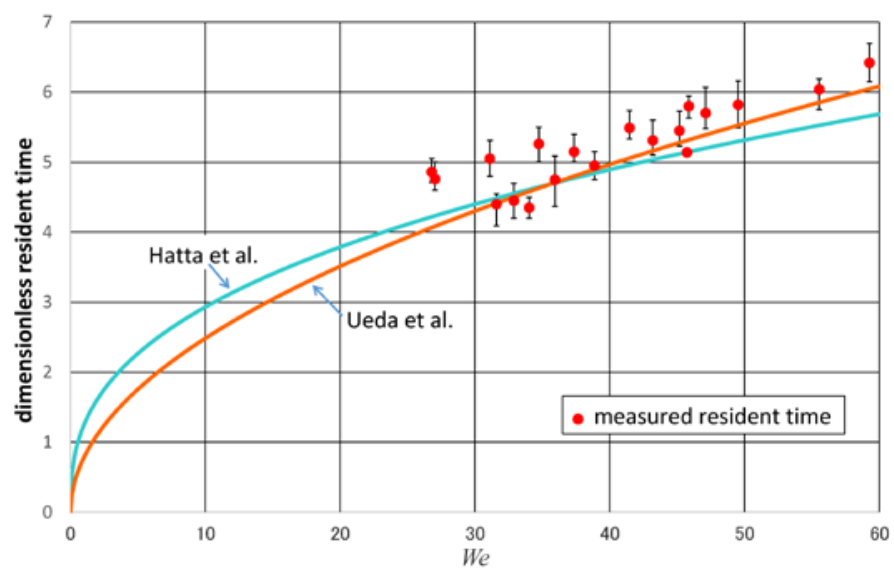

Figure 13: Empirical and theoretical relationship between the dimensionless residence time of drops on a hot surface and the Weber number. 
Table 1: Physical properties of the test solution.

\begin{tabular}{cccccc} 
& $\begin{array}{c}\text { density } \\
\left(\mathrm{kg} / \mathrm{m}^{3}\right)\end{array}$ & $\begin{array}{c}\text { surface } \\
\text { tension } \\
(\mathrm{mN} / \mathrm{m})\end{array}$ & $\begin{array}{c}\text { viscosity } \\
\left(\mathrm{mm}^{2} / \mathrm{s}\right)\end{array}$ & $\begin{array}{c}\text { specific } \\
\text { heat } \\
(\mathrm{kJ} / \mathrm{kgK})\end{array}$ & $\begin{array}{c}\text { thermal } \\
\text { conductivity } \\
(\mathrm{W} / \mathrm{mK})\end{array}$ \\
\hline $\begin{array}{c}\text { water } \\
\left(40^{\circ} \mathrm{C}\right)\end{array}$ & $0.992 \times 10^{3}$ & 69.6 & 0.658 & 4.18 & 0.628 \\
\hline $\begin{array}{c}\text { test liquid } \\
\left(20^{\circ} \mathrm{C}\right)\end{array}$ & $1.09 \times 10^{3}$ & 53.6 & 10.0 & 4.00 & 0.543 \\
$\begin{array}{c}\text { test liquid } \\
\left(40^{\circ} \mathrm{C}\right)\end{array}$ & $1.03 \times 10^{3}$ & 52.0 & 5.41 & 4.01 & 0.588 \\
$\begin{array}{c}\text { test liquid } \\
\left(50^{\circ} \mathrm{C}\right)\end{array}$ & $0.997 \times 10^{3}$ & 51.3 & 4.18 & 4.02 & 0.593 \\
$\begin{array}{c}\text { test liquid } \\
\left(80^{\circ} \mathrm{C}\right)\end{array}$ & $0.984 \times 10^{3}$ & 50.4 & 1.64 & 4.04 & 0.606
\end{tabular}


Table 2: List of experimental conditions.

\begin{tabular}{cccccc} 
Figure No. & $T_{w}\left({ }^{\circ} \mathrm{C}\right)$ & $d_{p}(\mathrm{~mm})$ & $v(\mathrm{~m} / \mathrm{s})$ & We & $T_{n}\left({ }^{\circ} \mathrm{C}\right)$ \\
\hline Figure 5 & 200 & 2.32 & 0.89 & 38 & 32 \\
Figure 6 & 350 & 2.34 & 0.92 & 39 & 30 \\
Figure 8 & 500 & 2.38 & 0.91 & 40 & 30 \\
Figure 9 & 500 & 2.17 & 1.25 & 67 & 40 \\
Figure 10 & 500 & 2.34 & 0.98 & 45 & 32
\end{tabular}

